\title{
Computer-Based Learning Module and the Educational Process for Women with Breast Cancer Who Desire Reconstruction
}

\author{
Albert Losken, MD \\ Department of Surgery, Emory Division of Plastic and Reconstructive Surgery, Atlanta
}

The term "doctor" has Latin roots meaning "to teach." As surgeons, we focus much of our early education and training on mastering surgical technique and managing sick patients. However, as doctors we are also required to teach. This educational process is not limited to students and colleagues, but as pointed out in this paper, applies to our interactions with patients as well. ${ }^{1}$ Lee et al. realize the importance of patient education as a crucial component of the consultation process. They have designed a computerbased learning model for patients with breast cancer who are interested in undergoing postmastectomy reconstruction. They emphasize the benefits of shared decisionmaking and how patients who are actively engaged in their own healthcare management will demonstrate greater compliance and improved satisfaction. This was demonstrated by querying breast reconstruction patients who had a standard surgical consultation and those who were shown a computer-based decision aid in addition to the standard consultation. Those patients who had the computer-based learning module felt that they had a greater role in choosing their reconstruction, were able to recall more options, and were more satisfied with the information provided. The authors felt that this educational module is useful in its ability to improve the shared decision-making process.

The decision process is important for any medical treatment plan or surgical procedure, and the benefits of affective educational tools cannot be overstated. This is even more important for something like breast reconstruction where (1) it is elective, and (2) there are many options. Breast cancer patients have a surge of emotions prior to mastectomy and are often overwhelmed with their

(C) Society of Surgical Oncology 2009

Published Online: 29 December 2009

A. Losken, MD

e-mail: albert_losken@emoryhealthcare.org choices regarding breast cancer management. To add reconstructive options to the mix will often complicate the process even more. As reconstructive surgeons, we need to provide patients with all the appropriate options and together decide on the best approach without making this more difficult than it needs to be. We have traditionally used tools such as diagrams, patient examples, and written educational brochures or books to describe the procedures. However, we now live in a very Internet- and technologysavvy world, and online or computer-based learning modules are going to become the standard of care. As educated consumers, patients today will often have already done some research prior to the consultation. Breast cancer patients are some of the highest personal users of the Internet, likely due to the large number of information sites and support groups. ${ }^{2,3}$ Patients have been shown to routinely use the Internet for information on breast reconstruction and are influenced by what they read. ${ }^{4}$ However, this is often not peer reviewed and can be biased or inaccurate. One study evaluated online resources for breast augmentation and found that $83 \%$ of the sites were biased towards a particular procedure, and another study similarly showed that $34 \%$ of the sites contained false or misleading information. ${ }^{5,6}$ Since patients are likely to use the Internet for research on breast reconstruction, it might be safer to refer them to societal or institutional sites (or educational modules such as the one proposed) with which we are familiar and that present information that we trust.

Having the ability to review the options before the consultation, and the content of the information is probably more important than the actual means of delivery, however, computer-based mechanisms in today's society hold the obvious advantages. Most patients are very comfortable using a computer and often have mobile access, which can also lend itself to portable educational modules. The way the authors distributed the information was effective, and all patients in that group were able to review the content 
prior to the consultation. As a generalization there are different scenarios that I have experienced when asked to discuss breast reconstruction with a patient. One extreme is the patient who comes in wanting reconstruction, asks very few questions, and is willing to have whatever option you feel is best. The other extreme is the patient who comes in knowing what type of reconstruction she wants, and is not interested in discussing other options. With the strong endorsement of the benefits of perforator flaps on the Internet or in communities, it is not uncommon these days for patients to come in requesting a deep inferior epigastric perforator (DIEP) or other perforator flap more so than any other technique. Other patients come in adamant not to have an implant-based reconstruction, for example, which occasionally does help narrow down the options. Although we prefer our patients to be educated on the various options, convincing them that a desired procedure might not be in their interest could also be difficult. After all, we have the benefit of experience and insight into breast reconstruction options and outcomes, which even the educated patient will often lack. Regardless of the extreme at which the consultation lies, it is our role to moderate the discussion and, although their involvement is critical, we need to steer the decision-making process towards the most appropriate and safest procedure for that particular patient.

The authors are to be congratulated on further trying to streamline the educational process for women with breast cancer who desire reconstruction. I am sure that this is greatly appreciated by most patients, who often have a thirst for additional information. Many institutions have put together educational material for their reconstruction patients, and I predict that we will continue to see the benefits of such education modules, whether traditional printed material, computerized or online. This would ideally be standardized in a peer-reviewed fashion to eliminate potential bias and misinformation and become available to every patient faced with the need to undergo breast reconstruction.

\section{REFERENCES}

1. Lee BT, Chen C, Yueh JH, et al. Computer-based learning module increases shared decision making in breast reconstruction. Ann Surg Oncol. 2009. doi:10.1245/s10434-009-0869-7.

2. Ziebland S, Chapple A, Dumelow C, et al. How the internet affects patients' experience of cancer: a qualitative study. BMJ. 2004;328:564.

3. Santoro E. Internet and information on breast cancer: an overview. Breast. 2003;12:424.

4. Losken A, Burke R, Elliott F, Carlson GW. Infonomics and breast reconstruction: are patients using the internet? Ann Plast Surg. 2005;54(3):247.

5. Gordon JB, Barot LR, Fahey AL, et al. The internet as a source of information on breast augmentation. Plast Reconstr Surg. 2001;107:171.

6. Jejurikar SS, Rovak JM, Kuzon WM, et al. Evaluation of plastic surgery information on the internet. Ann Plast Surg. 2002;49:460. 